\title{
Verification of filter efficiency of horizontal roughing filter by Weglin's design criteria and Artificial Neural Network
}

\author{
Biswajit Mukhopadhay ${ }^{1}$, Mrinmoy Majumder ${ }^{2}$, Rabindra Nath Barman ${ }^{3}$, Pankaj Kumar Roy ${ }^{2}$, and \\ Asis Mazumder ${ }^{2}$ \\ ${ }^{1}$ KMW\&SA, Kolkata, India \\ ${ }^{2}$ School of Water Resources Engineering, Jadavpur University, Kolkata, India \\ ${ }^{3}$ B. P. Poddar Institute of Management and Technology, Kolkata, India \\ Received: 9 June 2008 - Published in Drink. Water Eng. Sci. Discuss.: 8 July 2008 \\ Revised: 27 February 2009 - Accepted: 29 April 2009 - Published: 19 June 2009
}

\begin{abstract}
The general objective of this study is to estimate the performance of the Horizontal Roughing Filter (HRF) by using Weglin's design criteria based on 1/3-2/3 filter theory. The main objective of the present study is to validate HRF developed in the laboratory with Slow Sand Filter (SSF) as a pretreatment unit with the help of Weglin's design criteria for HRF with respect to raw water condition and neuro-genetic model developed based on the filter dataset. The results achieved from the three different models were compared to find whether the performance of the experimental HRF with SSF output conforms to the other two models which will verify the validity of the former. According to the results, the experimental setup was coherent with the neural model but incoherent with the results from Weglin's formula as lowest mean square error was observed in case of the neuro-genetic model while comparing with the values found from the experimental SSF-HRF unit. As neural models are known to learn a problem with utmost efficiency, the model verification result was taken as positive.
\end{abstract}

\section{Introduction}

Water is essential for life. Basically all human communities grow up centering some kind of water source. Apart from ground-water most of the people of the world depend on surface water as one of the main sources for drinking purposes. As surface water is unprotected and exposed, there is a possibility of feacal contamination. The main target of a water treatment procedure is the removal of chemical and bacteriological contamination and inactivation of disease causing organism. In conventional treatment of surface water, plain sedimentation and even prolonged storage are often used to separate the suspended solid concentration which is followed by flocculation by using chemicals to destabilize the suspended solids of smaller magnitude. In rural area water supply system, HRF is used to treat the surface water of high turbidity as it is a cheap alternative to the costly electrical powered water treatment systems (El-Taweel and Ali, 2004).

HRF is operated at filtration rates ranging from 0.3 to $1.5 \mathrm{~m} / \mathrm{h}$. And it could also remove the turbidity ranging from
50 to 1000 NTU. The use of HRF as a pre-filter reduces the solid loads within the SSF or Rapid Sand Filter (RSF) which is used as a pre-filter. The main objective of the present study was to calculate bacteria removal efficiency of SSF coupled HRF units (SSFHRF). The work also incorporates an investigation of the system of HRF with or without the SSF with respect to removal of solids and pathogenic organism (Barman et al., 2008).

The Hydraulic design of a filtration process in case of HRF is incorporated by different theories developed in the laboratories based on various field studies at different conditions. But for the rural area water supply by Multistage Filtration, use of HRF system before the SSF is commonly practiced. Now the conceptual filter theory for evaluation of efficiency of the filter in case of HRF is still based on the filtration theory described by Weglin (1996).

\section{Correspondence to:}

Biswajit Mukhopadhay

(biswajitmukherjee23@ rediff.com)

Published by Copernicus Publications on behalf of the Delft University of Technology. 


\subsection{Weglin's model}

When a particle in the water passes through a gravel bed filled up with gravel there is a chance that water particles may escape either through left or through right or on the surface of the gravel and if latter is the case the particles settled out. Hence, the probability of chance of the success of removal and the failure is $1 / 3$ and $2 / 3$. This is the basic of the Weglin's $1 / 3-2 / 3$ theory.

However, as the process of filtration continues through the multiple chambers of the HRF more of the particles get settled. So, along the flow path the quantity of the settleble particles get reduced in the multistage layers when it enters the filter. This theory has been practiced to formulate the models for a description of the filter efficiency as well as the removal efficiency of the HRF. According to the available filter theories and the Fick's law the filter efficiency can be expressed by the filter coefficient and is equal to,

$d c / d x=-\lambda c$

where $c=$ Solid concentration,

$x=$ Filter depth,

$\lambda=$ Filter coefficient or coefficient of proportionality.

From Eq. (1) it can be stated that the removal of the suspended particles is proportional to the concentration or the particles present in the water. This relation is taken as true only if the assumptions given next are also true.

The assumption of Weglin's theory is if a settable particle enters into a filter bed it can bypass a gravel grain either from the right or left or settle on the surface of the grain. Hence, chance to fall on the grain i.e. the success of removal is $1 / 3$ and $2 / 3$ rd. Thus, when the given quantities of settable solids enter into a filter bed; the quantity will reduce in successive layers as per the probability along the flow path.

The total length of the filter can be described as the number of parallel plates and act as a multistage reactor so the performance of the HRF can be ascertained on the basis of the results obtained from the small filter cells. The total suspended solid concentration after a length of $\Delta x$ of the filter cell can be expressed,

$C_{\text {outlet }}=\Sigma C_{\text {inlet }}^{e-\lambda i \Delta X}$

Where, $\lambda_{i}=$ Filter efficiency of each filter cell,

$\Delta x=$ Length of experimental filter cell,

$C_{\text {inlet }}$ and $C_{\text {outlet }}=$ Concentration of particles in the inlet and outlet of the filter.

From the Eq. (2) it is to be stated that after evaluating the filter depth (length) and the filter coefficient and the SS (suspended solids) concentration, the performance efficiency of the filter can be predicted. According to Weglin (1996), the effluent quantity for the $\mathrm{n}$ number of compartments is given by,

$C e=C_{0} * E_{1} * E_{2} * E_{3} * E_{4} * \ldots \ldots \ldots \ldots E_{n}$
$C_{0}=$ Concentration of the HRF influent,

$C_{e}=$ Concentration of the HRF effluent

$E_{1}, E_{2}, E_{3}, E_{4} \ldots \ldots \ldots \ldots E_{n}=$ Filtration efficiency for the each compartment (1,2, 3 respectively).

The basic expression for the above relationship is given by,

$C_{e}=C_{o} e-{ }^{\lambda L}$

where, $\lambda=$ Coefficient of filtration

$L=$ Length of the filter.

The Filter efficiency is given by,

$E=C_{e} / C_{0}=e-^{\lambda L}$

$C_{e}=C_{o} * E$

$E_{i}=$ Filter efficiency for $(i-1,2,3 \ldots n)$ compartments.

The values are obtained either from the table or graphical nomo-gram developed by Wegelin.

\subsection{Artificial Neural Network}

Artificial Neural Network is a distributed information processing system that has certain characteristics that resemble with the biological neural network of the human. The development of an artificial neural network as prescribed by ASCE (ASCE, 2000)., must follow the following basic rules,

1. Information must be processed at many single elements called nodes.

2. Signals are passed between nodes through connection links and each link has an associated weight that represents its connection strength.

3. Each of the nodes applies a non-linear transformation called as activation function to its net input to determine its output signal.

Advantage of ANN lies in its adaptive nature where "learning by example" replaces "programming" in solving problems. ANN is very appealing when very little or incomplete understanding of the problem to be solved is achieved. The intrinsic parallel architecture of ANN allows fast computations of solutions. ANN is widely applied in various fields of engineering and science due to its ability to recognize patterns, clustering complex dataset, accurate approximation and process based forecasts (Hassoun, 1995).

ANNs offer a relatively quick and flexible means of modeling and as a result, the application of ANN modeling was widely reported in various hydrological literatures (Zhang and Stanley, 1999; Ray and Klindworth, 2000). In the hydrological forecasting context, recent papers have reported that ANNs may offer a promising alternative for rainfall-runoff modeling (Tokar and Johnson, 1999), stream flow prediction (Clair and Ehrman, 1998; Imrie et al., 2000), reservoir inflow forecasting (Jain et al., 1999; Coulibaly et al., 2000) and 
in prediction of water quality parameters (Maier and Dandy, 1999). All the papers reported high degree of satisfaction with the neural network estimations. The development procedures of the ANN model is discussed next.

\subsubsection{Building the ANN}

Neural network can be of different type, like feed forward, radial basis function; time lag etc.The type of the network is selected with respect to the knowledge of input and output parameters and their relationship. Once the type of network is selected, selection of network topology is the next concern. Trial and error method is generally used for this purpose but many studies now prefer the application of genetic algorithm (Ahmed and Sarma, 2004). Genetic algorithms (GA) are search algorithms based on the mechanics of natural genetic and natural selection. The basic elements of natural genetics - reproduction, crossover, and mutation - are used in the genetic search procedure. A GA can be considered to consist of the following steps:

1. Select an initial population of strings.

2. Evaluate the fitness of each string.

3. Select strings from the current population to mate.

4. Perform crossover (mating) for the selected strings.

5. Perform mutation for selected string elements.

6. Repeat steps $2-5$ for the required number of generations.

\subsubsection{Training the ANN}

To encapsulate the desired input output relationship, weights are adjusted and applied to the network until the desired error was achieved. This is called as "training the network" (Bhatt et al., 2007). There is innumerable number of "training the network" algorithms available, among which, back-propagation is mostly prescribed (ASCE, 2000). In the present study, Quick Propagation (QP) and Conjugate gradient descent (CGD), both derived from basic backpropagation algorithms, were used as the training algorithm.

\subsubsection{Testing the ANN}

Some portion of the available historical dataset is used and known output is estimated and compared with the actual dataset to find an Mean Square Error (MSE). If the values found in this way are less than $1 \%$ then the networks are selected for forecast. Few part of the dataset is used for crossvalidation so that the network is not over-trained.

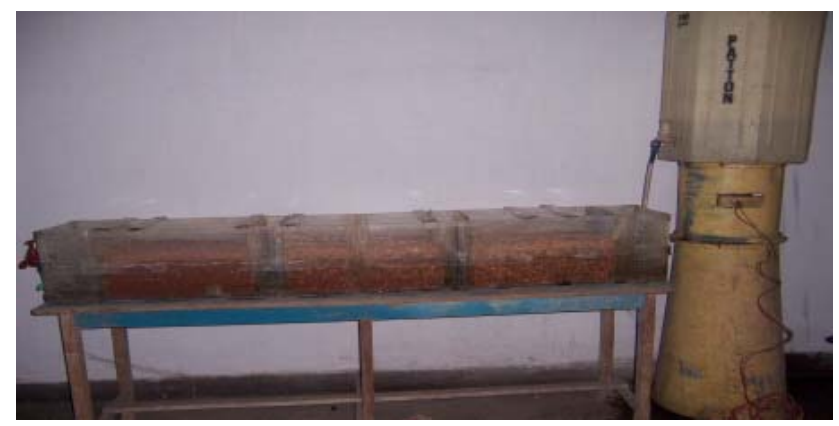

Figure 1. Model of horizontal roughing filter used in the experiment.

\section{Methodology}

\subsection{Preparation of the SSFHRF model}

A pilot plant was constructed in the Department of Water resources Engineering, Jadavpur University to investigate the objectives of the research study (Fig. 1). The structure of the plant was made up from the Fiber glass sheeting which consisted of three chambers of each $450 \mathrm{~mm} \times 300 \mathrm{~mm}$. The length of the whole filter can be extended but it will enforce an increased removal of turbidity which in turn will decrease the silt storage capacity of the HRF chambers. So, flushing interval would be very frequent.

The study has been carried out continuously for 70 days. If the plant was not been monitored continuously the actual picture of reduction of suspended solid concentration in the outlet could not be ascertained. However the filter was cleaned periodically by hydraulic flushing at the bottom after certain run period by observing the increasing filter resistance of the bed. This was checked through the rise of water level in the inlet chamber.

The filter medium namely gravel was placed in the three separate chambers starting from the coarse size to the finer ones in the direction of flow and the whole system was operated in series. The first compartment was filled up of gravel size $15 \mathrm{~mm}-10 \mathrm{~mm}$ having the average size $12.5 \mathrm{~mm}$ the second compartment consisted of average gravel size $7.5 \mathrm{~mm}$ and the third one of average size $2.5 \mathrm{~mm}$. Each compartment was being separated by the perforated fiber glass partition to avoid mixing of the gravels of different chambers. The filter bed was provided with the under drainage system to enable flushing after a certain running period of interval for hydraulic sludge extraction by observing the filter resistance (Fig. 2). A constant flow rate of $0.75 \mathrm{~m} / \mathrm{h}$ was maintained through all the compartments by the help of a peristaltic pump. The suspended solids (SS) concentration of raw water for all the chambers at the inlet and the SS concentration at the out let was measured by the help of standard procedure describe in the Standard methods. Sampling from the investigation was done at least three times of week for a 

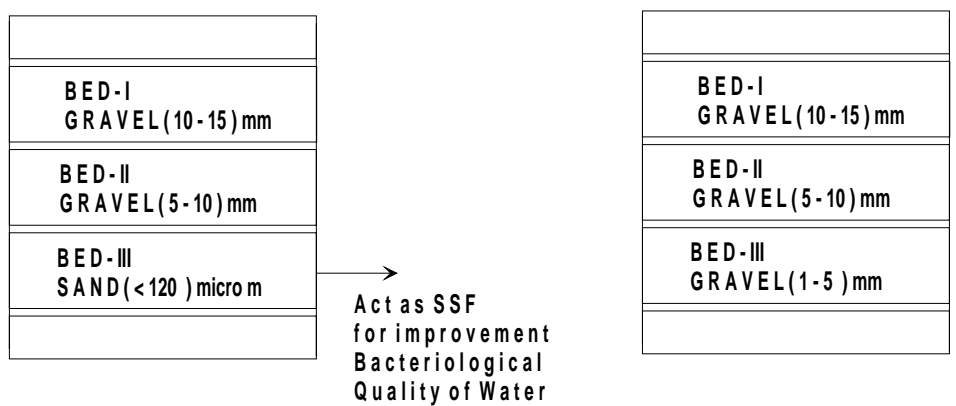

INLET

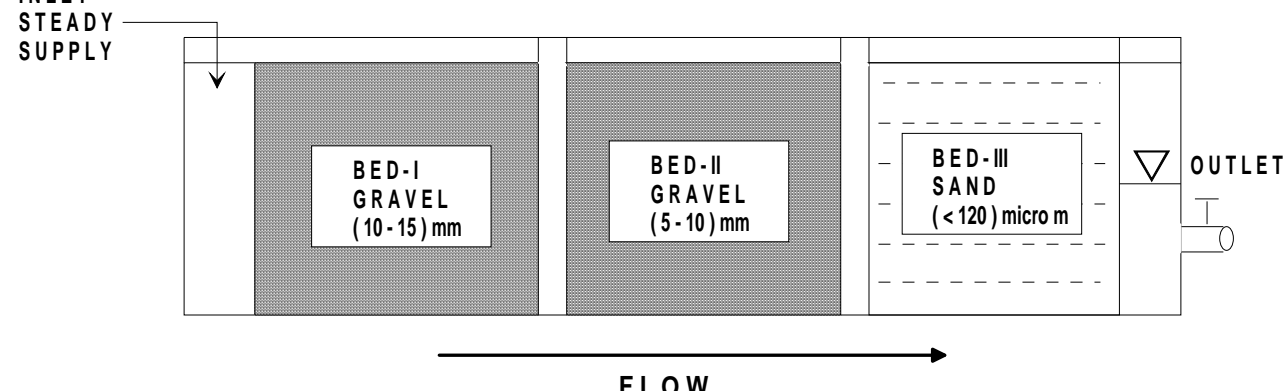

FLOW

Figure 2. Basic layout of the HRF and HRF filter bed that was used in the experiment.

Table 1. E-value for different compartment and efficiency value for the total filter.

\begin{tabular}{lllll}
\hline $\begin{array}{l}\text { Effective size } \\
(\mathrm{dg})\end{array}$ & $\begin{array}{l}\text { Filtration rate } \\
(\mathrm{m} / \mathrm{h})\end{array}$ & $\begin{array}{l}\text { Length of } \\
\text { compt. }\end{array}$ & $\begin{array}{l}\text { E-value } \\
(\%)\end{array}$ & $\begin{array}{l}\text { Total E-value } \\
(\mathrm{dec})\end{array}$ \\
\hline $5 \mathrm{~mm}$ & $0.75 \mathrm{~m} / \mathrm{h}$ & $0.45 \mathrm{~m}$ & $E_{1}=21.3$ & 0.026 \\
$10 \mathrm{~mm}$ & $0.75 \mathrm{~m} / \mathrm{h}$ & $0.45 \mathrm{~m}$ & $E_{2}=19.6$ & \\
$15 \mathrm{~mm}$ & $0.75 \mathrm{~m} / \mathrm{h}$ & $0.45 \mathrm{~m}$ & $E_{3}=26.0$ & \\
\hline
\end{tabular}

period of 70 days. The experiment was carried out both in low flow (dry season) and high flow (rainy season) periods during the scan of 70 days .the local pond water was used as raw water which has the concentration of suspended solids ranges from $40 \mathrm{mg} / \mathrm{l}$ to $150 \mathrm{mg} / \mathrm{l}$.According to Weglin's design guide line this range is medium range of concentration $(100-300) \mathrm{mg} / \mathrm{l}$ for which filtration rate is $0.75 \mathrm{~m} / \mathrm{h}-1.0 \mathrm{~m} / \mathrm{h}$ are recommended. So a constant flow $0.75 \mathrm{~m} / \mathrm{h}$ was chosen in carrying out the experiment (Table 1).

The Table 2a depicts the concentration of the HRF effluent as found from the HRF filter developed for the present study. The corresponding runtime and initial concentration is also given in the table.

The Table $2 b$ depicts the concentration of the effluent as calculated from the Weglin's 1/3-2/3 theory (Eq. 2).

The third model was developed by artificial neural network and with the help of dataset taken from the HRF made in the laboratory. As neural network learn from the results rather than from the reasons, the model tried to learn the patterns that exist between the inputs and the output of the SSFHRF model. A detailed description of ANN is given in Sect. 1.2.

\subsection{Application of Neuro-Genetic model and Weglin's model}

Run time and filtration efficiency of the HRF input chamber was taken as input and filtration efficiency at the output chamber was taken as output. Table 3 depicts the details of the training methodology of the neuro-genetic models. The dataset for the training was the same dataset that was found from the SSFHRF setup and used in the formula prescribed by Weglin (Eqs. 1 and 2) to generate the output shown in Table $2 b$.

$70 \%$ of the available dataset was used as training, $15 \%$ for testing and rest was used for cross validation .Four feed forward neural network is built. Two of which was trained with QP and other two by CGD. The genetic algorithm was applied to select the topology of all the four networks from possible forty solutions. Sixty combinations were forced from these patterns allowing $90 \%$ cross over rate and $20 \%$ mutation capability.

The training as explained in Sect. 1.2 was continued until the MSE drops below 1\%.Each of the network was trained for 100 times with 100000 iterations per training. 
Table 2a. Summary table of the results of the SSFHRF model.

\begin{tabular}{|c|c|c|}
\hline $\begin{array}{c}\text { Run time } \\
\text { (Days) }\end{array}$ & $\begin{array}{c}C_{0} \\
(\mathrm{mg} / \mathrm{l})\end{array}$ & $\begin{array}{c}C_{e} \\
(\mathrm{mg} / \mathrm{l})\end{array}$ \\
\hline 3 & 12.5 & 4.02 \\
\hline 5 & 9.8 & 4.38 \\
\hline 7 & 14.6 & 4.62 \\
\hline 10 & 18.8 & 4.89 \\
\hline 12 & 20.7 & 4.86 \\
\hline 14 & 25.8 & 4.65 \\
\hline 17 & 16.7 & 3.89 \\
\hline 19 & 19.6 & 3.02 \\
\hline 22 & 21.65 & 4.02 \\
\hline 24 & 22.8 & 4.63 \\
\hline 27 & 38.8 & 4.56 \\
\hline 30 & 24.4 & 2.8 \\
\hline 32 & 30.1 & 3.8 \\
\hline 35 & 48.8 & 3.62 \\
\hline 38 & 42.4 & 2.8 \\
\hline 40 & 48 & 4.6 \\
\hline 42 & 58.6 & 4.32 \\
\hline 46 & 72 & 5.2 \\
\hline 48 & 84 & 6 \\
\hline 51 & 116 & 3.8 \\
\hline 53 & 67 & 4.3 \\
\hline 54 & 98 & 3.9 \\
\hline 55 & 47 & 2.6 \\
\hline 58 & 50 & 3.43 \\
\hline 60 & 50.4 & 7 \\
\hline 61 & 33.8 & 4.26 \\
\hline 62 & 22.5 & 4.36 \\
\hline 64 & 33.6 & 2.9 \\
\hline 67 & 48.6 & 5.6 \\
\hline 68 & 47.7 & 3.1 \\
\hline 70 & 33.2 & 3.1 \\
\hline
\end{tabular}

After the training, average absolute error achieved from the four networks named QP1 and QP2 for the 2 networks trained in QP and CGD1 and CGD2 for the networks trained in CGD were 0.08921, 0.0921, 0.07721 and 0.08721 respectively.The average MSE from the training of these networks were $0.09,0.097,0.00993$ and 0.0978 respectively which indicates that all the networks had sufficiently learned the present problem.

The networks were tested with two patterns (15\% of the total dataset) and the average MSE and average absolute error was found as $0.79,0.77,0.5,0.65$ and $0.87,0.86,0.75$, 0.85 respectively for QP1, QP2, CGD1 and CGD2.

CGD1 was selected as the best performing network due to the least absolute and mean square error achieved during the training and testing procedures.
Table 2b. Summary table of the results from Weglin's model.

\begin{tabular}{|c|c|c|}
\hline $\begin{array}{l}\text { Run time } \\
\text { (Days) }\end{array}$ & $\begin{array}{c}C_{0} \\
(\mathrm{mg} / \mathrm{l})\end{array}$ & $\begin{array}{c}C_{e} \\
(\mathrm{mg} / \mathrm{l})\end{array}$ \\
\hline 3 & 12.5 & 0.33 \\
\hline 5 & 9.8 & 0.25 \\
\hline 7 & 14.6 & 0.38 \\
\hline 10 & 18.8 & 0.49 \\
\hline 12 & 20.7 & 0.54 \\
\hline 14 & 25.8 & 0.67 \\
\hline 17 & 16.7 & 0.43 \\
\hline 19 & 19.6 & 0.51 \\
\hline 22 & 21.65 & 0.56 \\
\hline 24 & 22.8 & 0.57 \\
\hline 27 & 38.8 & 1 \\
\hline 30 & 24.4 & 0.63 \\
\hline 32 & 30.1 & 0.78 \\
\hline 35 & 48.8 & 1.27 \\
\hline 38 & 42.4 & 1.1 \\
\hline 40 & 48 & 1.25 \\
\hline 42 & 58.6 & 1.52 \\
\hline 46 & 72 & 1.87 \\
\hline 48 & 84 & 2.18 \\
\hline 51 & 116 & 3.01 \\
\hline 53 & 67 & 1.34 \\
\hline 54 & 98 & 2.55 \\
\hline 55 & 47 & 1.22 \\
\hline 58 & 50 & 1.3 \\
\hline 60 & 50.4 & 1.31 \\
\hline 61 & 33.8 & 0.88 \\
\hline 62 & 22.5 & 0.59 \\
\hline 64 & 33.6 & 0.87 \\
\hline 67 & 48.6 & 1.26 \\
\hline 68 & 47.7 & 1.24 \\
\hline 70 & 33.2 & 0.86 \\
\hline
\end{tabular}

\subsection{SSFHRF model verification criteria}

The verification of the SSFHRF model was assessed by comparing its response with the output from the Weglin's model and the neuro-genetic model. The evaluation criteria included percentage MSE, correlation coefficient $(r)$, coefficient of efficiency (C.E.) and Standard Deviation (STDEV).

$\% \mathrm{MSE}=((T p-O p) / T p) \times 100$

$$
\begin{aligned}
& r=\left[\sum_{n}((T p-T m)(O p-O m)) /\right. \\
& \left.\quad\left(\sum_{1}^{n}(T p-T m)^{2} \sum_{1}^{n}(O p-O m)^{2}\right)^{1 / 2}\right] \\
& \text { C.E. }=1-\left(\sum_{1}^{n}(T p-O p)^{2} / \sum_{1}^{n}(T p-T m)^{2}\right)
\end{aligned}
$$


Table 3. Comparison of CGD1 and Weglin's model with respect to the HRF setup.

\begin{tabular}{lcccc}
\hline & MSE & $r$ & C.E & STDDEV \\
\hline CGD1 & 0.63 & 0.98 & 0.988 & 0.095 \\
Weglin's model & 3.32 & 0.14 & 0.408 & 1.78 \\
\hline
\end{tabular}

$\mathrm{STDDEV}=\frac{\sum_{1}^{n}(T n-\bar{T} n)^{2}}{n}$

Where, $T p$ is the target value for the $p$-th pattern; $O p$ is the estimated value for the $p$-th pattern, Tm and $O m$ are the mean target and estimated values respectively and $n$ is the total number of patterns. MSE shows the measure of the difference between target $(T p)$ and estimated $(O p)$ value, $r$ defines the degree of correlation between two variables. C.E. Criterion has the basis of standardization of the residual variance with initial variance (Nash and Sutcliffe, 1970).

In this criterion, a perfect agreement between the observed and estimated output yields an efficiency of one. A negative efficiency represents lack of agreement and zero agreement means all the estimated value is equal to the observed mean. STDDEV is the measure of deviation of the estimated value from the target output. A perfect match between observed data and model simulations is obtained when STDDEV approaches 0.0 (Yitian and Gu, 2003).

\section{Results and discussion}

In order to compare the performance of the SSFHRF laboratory model with ANN and Weglin's model; MSE, $r$, C.E, STDDEV were calculated between observed values taken from the SSFHRF setup and computed values estimated by the neuro-genetic model (CGD1) and Weglin's model (Eq. 2). The verification criteria selected for the present study was prescribed by Nash and Sutcliffe (1970) for the selection of the best performing model.

According to the results from the performance validating criterias, CGD1 was found to be more similar than the Weglin's model with the output from SSFHRF setup. The MSE values obtained were 0.63 and 3.32 respectively for CGD1 and the Weglin's model (Table 3).

CGD1 values were found to be 5.27 times (MSE) nearer to the values found from the SSFHRF model than the values estimated by the Weglin's model. Estimated values from CGD1 gave high model efficiency (98\%) whereas Weglin's model had an efficiency of $40.8 \%$ i.e. the neuro-genetic model was 2.4 times more efficient than the Weglin's model when compared with the output of SSFHRF. The STDDEV of CGD1 was found to be as 0.095 where as the same for the ANN model was 1.78. So the ANN model was 18.7 times closer to the SSFHRF values than Weglin's model. The values from CGD1 were found to be $98 \%$ related with the SSFHRF values but Weglin's model was found out to be only $14 \%$ related with the same values.

CGD1 model was found to be supportive of the results from the SSFHRF filter but the results from the Weglin's model was showing negative decision. But as neuro-genetic models learn from effects than from the causes and many author supports the use of neuro-genetic models in solution of hydrological problems the authors of the present study take the outcome from the neuro-genetic model as verifiable results for the SSFHRF unit.

\section{Conclusions}

Filtration efficiency of a horizontal roughing filter was estimated with a laboratory developed filter model with a sand filter as a pretreatment unit. The efficiency of the HRF was compared with neuro-genetic model and the 1/3-2/3 model of Weglin. From the performance validation criterions it was found that filter efficiency achieved from the experimental model was supported by the neuro-genetic model whereas the results from the filter do not agree with the Weglin's concept. The reason behind this contradictory decisions about the SSFHRF model can be due to the Weglin's consideration of some parameters and constants which changes with change in climatic and experimental conditions of the setup but in case of neural network model, it considered no such parameters and simply follows the pattern of the input with output in the problem domain. Neural network models are nowadays hugely used in different hydrologic estimations and are popular for their accuracy and efficiency. Many papers have been published in this regard. As the results from the present experimental HRF was supported by a neuro-genetic model, the verification of the laboratory model was taken as positive.

Edited by: L. Rietveld

\section{References}

Ahmed, J. A. and Sarma, A. K.: Genetic Algorithm for Optimal Operating Policy of a Multipurpose Reservoir, J. Water Res. Manage., 19, 145-161, 2005.

ASCE Task Committee on Application of Artificial Neural Networks in Hydrology: Artificial neural networks in Hydrology I: Preliminary concepts, ASCE Journal of Hydrologic Engineering, 5(2), 115-123, 2000.

Barman, R. N., Mukhopadhaya, B., Majumder, M., Roy, P. K., and Mazumdar, A.: Estimation And Calculationof A Relationship Between Dispersion Number, Reynolds Number, Porosity And Hydraulic Gradient in Horizontal Roughing Filter, Journal of Agricultural, Food, and Environmental Sciences, 2, 1, http://www.scientificjournals.org/journals2008/j_of_ agriculture1_2008.htm, 2008.

Bhatt, V. K., Bhattacharya, P., and Tiwari, A. K.: Application of artificial neural network in estimation of rainfall erosivity, Hydrol. J., 1-2, 30-39, 2007. 
Clair, T. A. and Ehrman, J. M.: Using neural networks to assess the influence of changing seasonal climates in modifying discharge, dissolved organic carbon, and nitrogen export in eastern Canadian rivers, Water Resour. Res., 34(3), 447-455, 1998.

Coulibaly, P., Anctil, F., and Bobee, B.: Daily reservoir inflow forecasting using artificial neural networks with stopped training approach, Hydrology, 230(3-4), 244-257, 2000.

El-Taweel, G. E. and Ali, G. H.: Evaluation of Roughing and Slow Sand Filters for Water Treatment, Water Air Soil Poll., 120(1/2), 21-28, 2004.

Hassoun, M.: Fundamental of Artificial Neural Networks, Massachusetts Institute of Technology, 1, 1995.

Imrie, C. E., Durucan, S., and Korre, A.: River flow prediction using neural networks: Generalization beyond the calibration range, Hydrology, 233(3-4), 138-154, 2000.

Jain, S. K., Das, A., and Srivastava, D. K.: Application of ANN for reservoir inflow prediction and operation, J. Water Res. Pl.ASCE, 125(5), 263-271, 1999.

Maier, H. R. and Dandy, G. C.: Empirical comparison of various methods for training feed-forward neural networks for salinity forecasting, Water Resour. Res., 35(8), 2591-2596, 1999.
Nash, J. E. and Sutcliffe, J. V.: River flow forecasting through conceptual models, J. Hydrol., 10, 282-290, 1970.

Ray, C. and Klindworth, K. K.: Neural networks for agrichemical vulnerability assessment of rural private wells, Hydrol. Eng., 5(2), 162-171, 2000.

Tokar, A. S. and Johnson, P. A.: Rainfall-runoff modeling using artificial neural networks, Hydrol. Eng., 4(3), 232-239, 1999.

Yitian, L. and Gu, R. R.: Modeling Flow and Sediment Transport in a River System Using an Artificial Neural Network, J. Environ. Manage., 31, 1, 122-134, 2003.

Wang, Q. J.: The genetic algorithm and its application to calibrating conceptual rainfall-runoff models, Water Resour. Res., 27(9), 2467-2471, 1991.

Wardlaw, R. and Sharif, M.: Evaluation of genetic algorithms for optimal reservoir system operation, J. Water Res. Pl.-ASCE, 125(1), 25-33, 1999.

Zhang, Q. and Stanley, S. J.: Real-time treatment process control with artificial neural networks, J. Environ. Eng., 125(2), 153160, 1999. 